\title{
Confirmation of the five-factor structure of the Parent Global Report version of the Alabama Parenting Questionnaire in a Polish community sample
}

\author{
Małgorzata Święcicka ${ }^{1} \cdot$ Małgorzata Woźniak-Prus ${ }^{2} \cdot$ Małgorzata Gambin $^{1} \cdot$ Maciej Stolarski $^{1}$
}

(C) The Author(s) 2019

\begin{abstract}
Since parenting practices have been shown to play an important role in the development of a child's emotional, cognitive and social functioning, it is important to reliably measure this construct across various cultures and countries. A widely used instrument to assess parenting practices is the Alabama Parenting Questionnaire (APQ). However, no previous studies have verified the five-factor structure of this measure using confirmatory factor analysis. The aim of this study was to verify factor structure and examine psychometric properties of the Parent Global Report version of the APQ in a Polish sample. A total of 911 mothers and 497 fathers of children in the age range of 6-13 years from the community sample completed the Alabama Parenting Questionnaire as well as the Rating Scales for Parents assessing symptoms of attention deficit hyperactivity disorder (ADHD) and oppositional-defiant disorder (ODD). Confirmatory factor analysis indicated that the five-factor model is characterized by a good fit in the Polish sample of mothers and quite a good fit in the sample of fathers. The Polish version of the APQ has a good construct validity. Children's ODD symptoms were positively correlated with negative parenting practices and negatively with positive parenting practices. Children's ADHD symptoms were the most strongly correlated with the inconsistent discipline subscale. Relations between ADHD and ODD symptoms and positive parenting practices were lower than with negative parenting practices. Our study confirms the five-factor structure of the Polish version of the APQ for parents and shows that parenting practices can be reliably measured in a Polish sample with the use of the Parent Global Report version of the APQ.
\end{abstract}

Keywords Alabama Parenting Questionnaire (APQ) - Parenting practices · Confirmatory factor analysis · ADHD symptoms · ODD symptoms

Parenting is an important factor affecting the course of human development. From a developmental psychopathology perspective (Cicchetti 2006), the role of parents in a child's development can be analyzed in the context of both normal and disordered development, and parenting may be considered either a protective factor or a risk factor. Over the long history of research on parental impact on a child's adjustment, various

Electronic supplementary material The online version of this article (https://doi.org/10.1007/s12144-019-00340-8) contains supplementary material, which is available to authorized users.

Małgorzata Święcicka

mswiec@ psych.uw.edu.pl

1 Faculty of Psychology, University of Warsaw, ul. Stawki 5/7, 00-183 Warsaw, Poland

2 Institute of Psychology, The Maria Grzegorzewska University, ul. Szczę́liwicka 40, 02-353, Warsaw, Poland constructs relating to different aspects of parenting have been proposed. Parenting practices are one of the key parenting dimensions, defined as specific actions taken by parents during interactions with a particular child in a given situation to socialize him or her (Darling and Steinberg 1993). Therefore, they have been shown to have a direct influence on various aspects of a child's functioning (Darling and Steinberg 1993). In particular, previous studies (Ellis and Nigg 2009; Hawes et al. 2013; Johnston and Mash 2001; Rielly et al. 2006; Stormshak et al. 2000) have shown that various parenting practices play a role in the development and maintenance of symptoms of attention deficit hyperactivity disorder (ADHD) and disruptive behavior problems like symptoms of oppositional defiant disorder (ODD) or conduct disorder (CD), in both clinical and community samples. Moreover, several parenting practices are considered to be important targets for change in interventions for children with behavior problems (Chronis-Tuscano et al. 2011; Hinshaw et al. 2000). It is therefore important to have access to reliable and valid measures 
that assess various types of parenting practices and that can be used in a range of countries and cultures for both clinical and research purposes.

Several researchers (e.g. Bøe et al. 2014; Gershoff et al. 2010) have highlighted the need for more studies on the association between parenting and children's mental health using non-North American samples. Such research could determine whether theories and recommendations developed based on findings from North American samples may be applied to parents and children in other countries and cultures. The Alabama Parenting Questionnaire (APQ; Frick 1991) is a popular measure of parenting practices that allows evaluation of various parenting behaviors that have been differentially linked to the development and maintenance of a child's behavioral issues. However, previous studies did not verify the original five-factor structure of this measure using confirmatory factor analysis. Therefore, the aim of the current study was to verify the factor structure and to examine psychometric properties of the Parent Global Report version of the APQ in a Polish sample.

\section{Relationship between Parenting Practices and Child's Externalizing Behavior Problems}

Various effective and ineffective parenting practices have been identified that may improve or reduce the quality of a child's adjustment (Amato and Fowler 2002). Many studies (Earth et al. 2009; Frick et al. 1999; Stormshak et al. 2000; Strassberg et al. 1994) have demonstrated that punitive disciplinary practices, especially corporal punishment, can contribute to the emergence of disruptive behaviors, in particular, aggression, in children. Poor parental supervision has been found to be a predictor of oppositional-defiant and conduct problems in both children and adolescents (Frick et al. 1999; Racz and McMahon 2011). Moreover, inconsistent or timid parental discipline, such as failure to follow previously announced disciplinary rules or hesitation in applying disciplinary practices, have been shown to be one of the risk factors for the development of ADHD, ODD and conduct problems in children and adolescents (Burke et al. 2008; Ellis and Nigg 2009; Frick et al. 1999; Hawes et al. 2013; Martel et al. 2011, 2012).

These associations are likely to be complex, incorporating genotype-environment correlation, parent-driven effects, child-driven effects and recursive processes (Ullsperger et al. 2016). Previous studies (Martel et al. 2011; Martel et al. 2012; Nigg et al. 2010; Sonuga-Barke et al. 2009), for example, have demonstrated that specific genetic influences (associated with dopaminergic neurotransmission) only increase vulnerability to ADHD (in particular, the hyperactivity-impulsivity domain) in the presence of inconsistent parenting. It seems that negative parenting practices contribute to disruptive behavior problems through various coercive developmental sequences of negative parent-child interactions (e.g. Burke et al. 2008; Patterson 1982, 2002).

Child externalizing behaviors have also been shown to be associated with low levels of positive parenting, such as use of positive reinforcement and parental involvement (e.g. providing support and showing positive feelings for a child, spending time with him or her; Chronis et al. 2007; Frick et al. 1999; Pettit et al. 1997; Stormshak et al. 2000). Some studies (e.g. Ellis and Nigg 2009; Frick et al. 1999; Li and Lee 2012) have revealed lower relationships between aggressive, oppositional, and hyperactivity symptoms with positive parenting practices than with negative parenting practices. In particular, weaker relationships have been shown between a child's disruptive behaviors and positive reinforcement than with involvement (Ellis and Nigg 2009; Frick et al. 1999). Overall, there is far less research on the topic of relations of disruptive behavior problems to positive parenting practices than to negative parenting (see Li and Lee 2012 for a review).

\section{Previous Studies on the Psychometric Properties of the APQ}

Since parenting practices play an important role in child development, and particular parenting behaviors are differentially related to disruptive behaviors in children and adolescents, it is important to have access to valid and reliable measures to assess those practices. Researchers have typically used questionnaires (parental self-report or child report), structured interviews, and observation techniques to assess parenting practices (Hawes and Dadds 2006; Hurley et al. 2014; Locke and Prinz 2002). Questionnaires are the most commonly used technique because of their low cost and ease of administration and interpretation.

A significant amount of research has been conducted using the APQ (Frick 1991). There are two versions of this instrument: one for parents (Parent Global Report) and one for children (Child Global Report) (Frick 1991). The APQ uses five subscales to measure five dimensions of parenting practices: (i) involvement, i.e. the parent's participation in the child's life; (ii) positive parenting, defined as the use of positive reinforcement (praise and material rewards); (iii) poor monitoring/ supervision, i.e. paying insufficient attention to what the child is doing; (iv) inconsistent discipline, i.e. inconsistent application of disciplinary rules; and (v) corporal punishment. These dimensions were selected based on an analysis of the literature (Shelton et al. 1996), which has shown that they are particularly strongly associated with disruptive behavior in children. The APQ is considered to be an accurate tool, with acceptable psychometric properties (Hurley et al. 2014). Shelton et al. (1996) have demonstrated that the five APQ subscales have acceptable stability and discriminant validity and are 
uncorrelated with measures of social desirability. Studies using the APQ (Dadds et al. 2003; Essau et al. 2006; Shelton et al. 1996; Frick et al. 1999) have generally reported that the internal consistency of individual subscales is high or moderate for the positive dimensions of parenting practices, and moderate or low for the negative dimensions. The APQ has been particularly useful for investigating the effectiveness of therapy for parents whose children have behavior problems (Feinfield and Baker 2004; Hawes and Dadds 2006; Hinshaw et al. 2000) and on delineating mechanisms of change in child and adolescent treatment (e.g. demonstrating that modification of specific parenting practices leads to improvements in a child's adjustment over time; Chronis-Tuscano et al. 2011; Hinshaw et al. 2000). A significant number of studies (e.g. Dadds et al. 2003; Essau et al. 2006; Frick et al. 1999; Martel et al. 2012; Shelton et al. 1996) have demonstrated anticipated links between APQ subscales and: (i) the symptoms of externalizing disorders; (ii) the social, emotional and school-related functioning of children; and (iii) various aspects of parentchild relationships.

The APQ has been used in various countries outside the United States, such as: Australia (Dadds et al. 2003), Germany (Essau et al. 2006), Spain (Molinuevo et al. 2011); and Italy (Esposito et al. 2016). Various adaptations to different countries, languages and age groups (Clerkin et al. 2007; Dadds et al. 2003; de la Olsa et al. 2014; Esposito et al. 2016; Essau et al. 2006; Molinuevo et al. 2011) have revealed that this measure is characterized by acceptable or good reliability and validity. Previous studies have used exploratory factor analysis to investigate the factor structure of the APQ and one of these studies (Essau et al. 2006) found that the Child Global Report version of the APQ has a five-factor structure, whereas other demonstrated that the Parent Global Report version of the APQ has a two, three or four-factor structure (Esposito et al. 2016; Molinuevo et al. 2011; Zlomke et al. 2014). However, none of these studies have verified the fivefactor structure of the instrument using confirmatory factor analysis (CFA), which allows researchers to test whether the data fit a hypothesized measurement model based on theory or/and previous research. Since prior research (e.g. ChronisTuscano et al. 2011; Ellis and Nigg 2009; Frick et al. 1999; Hawes and Dadds 2006; Hinshaw et al. 2000) has revealed that differentiation of the five types of parenting practices has important research and clinical utility, further studies aimed at verifying the original five-factor structure of various versions of the APQ, as well as its psychometric properties across various cultures and countries, are needed.

\section{Current Study}

The aim of the present study was to verify the factor structure and evaluate the psychometric properties of the Polish Parent
Global Report version of the APQ to provide a valid and reliable questionnaire of parenting practices that could be useful in diagnosis and treatment of children with disruptive behavior problems. Moreover, the Polish version of the APQ would allow researchers to test whether theories and recommendations developed based on findings in North American and Western European samples may be applied to parents and children in other countries and cultures - in this case, the Polish sample. Therefore, this study had two objectives and is divided into two parts. Firstly, based on confirmatory factor analysis, we verified the original five-factor structure of the APQ in a Polish sample (Study 1). Secondly, we examined the construct validity of the Polish version of the APQ by investigating associations between parenting practices and child's ADHD and oppositional-defiant symptoms (Study 2). As several studies (e.g. Gambin and Święcicka 2015, 2016; Marcus and Barry 2011; Nikolas and Burt 2010) have provided support for the importance of investigating externalizing disorders as continuous behavioral dimensions (as opposed to discrete categories), we measured severity of ADHD and ODD symptoms dimensionally in a community sample. Symptoms of ADHD and ODD were reported by parents who have opportunities to observe the children under a variety of circumstances and for long periods of time (De Los Reyes and Kazdin 2005; Faraone et al. 1995).

Cronbach and Meehl (1955) argued that demonstrating construct validity requires establishing that a given test relates to the measures of other equivalent constructs in theoretically predictable ways. Furthermore, Smith (2005) proposed that investigation of construct validity requires the following steps: careful theory specification, development of informative hypothesis tests, use of sound research design; examination of the degree to which observations confirm hypotheses, and an ongoing revisions of both theory and measures. To this end, we have explored associations between APQ subscales and ADHD and ODD symptoms basing on theories and previous studies (described above) that have emphasized and demonstrated that (i) negative parenting practices contribute to development of disruptive behavior problems through various coercive developmental sequences of negative parent-child interactions; (ii) differences in relationships between ADHD and ODD symptoms, and positive versus negative parenting practices exist. Therefore, to test construct validity we put forward these three hypotheses: H1: High levels of negative parenting practices (e g. corporal punishment, poor monitoring, inconsistent discipline) and low levels of positive parenting practices would be associated with elevated rates of ODD symptoms; H2: ADHD symptoms, especially the hyperactivity-impulsivity domain, would be particularly linked with inconsistent discipline; H3: Relations between child's symptoms and negative parenting practices would be stronger than those between child's symptoms and positive parenting. Previous research has shown that mothers and 
fathers differ in some aspects of parenting behaviors (Bögels and Phares 2008; Grossmann et al. 2002; Paquette 2004). Mothers are usually more involved in child rearing and focused on providing care and safety. Fathers are often play partners who support child's exploration and independence. Differences between the parents in various parenting practices have been also demonstrated, e.g. mothers are more willing to positive reinforce their children than fathers (Gryczkowski et al. 2010). Finally, previous findings suggested that the associations between parenting practices and child's externalizing disorder symptoms could depend on the gender of the parent (Ellis and Nigg 2009; Gryczkowski et al. 2010). Therefore we conducted all analyses for mothers and fathers separately.

\section{Study 1}

\section{Method}

\section{Participants}

A total of 911 mothers and 497 fathers completed the Polish version of the APQ for 994 children (516 girls and 478 boys) in the age range of 6-13 years (mean age: 9.5 years). We used a convenience non-probability sampling technique to select participants for inclusion in the sample. The students were drawn from 37 schools located in the Mazovian district in Poland. The majority of children $(58,6 \%)$ were from a city area, $25,3 \%$ were from a town and $16,1 \%$ were from rural areas. Moreover, $47.1 \%$ of mothers reported having higher education, $36.3 \%$ secondary education, $12.6 \%$ vocational education and $4 \%$ primary education, whereas $33.2 \%$ of fathers reported having higher education, $41,4 \%$ secondary education, $20.9 \%$ vocational education and $4.5 \%$ primary education.

\section{Measures}

The Parent Global Report version of the APQ (Frick 1991) comprises 42 items divided into five parenting constructs: parental involvement, use of positive reinforcement, poor parental monitoring and supervision, inconsistent discipline and corporal punishment. The respondent is asked to rate each item on a five-point Likert-type scale, ranging from 1 (never) to 5 (always). The APQ also includes seven additional items that measure specific disciplinary practices other than corporal punishment. These items were included to avoid a negative bias toward corporal punishment items. In past research (Shelton et al. 1996), the internal consistency of the five scales has been moderate ( $\alpha=0.63$ to 0.80$)$. The APQ was adapted and translated into Polish according to guidelines for the translation of instruments in cross-cultural research
(Brislin 1970). We used a high-quality translation, blind back-translation, and input from Polish mental health professionals; we also piloted the instrument in the target population.

\section{Procedure}

Each school principal, individual classroom teachers and the University of Warsaw Institutional Review Board granted permission for the study. The research was conducted by trained students and psychologists, who distributed questionnaires and information about the study to parents during school meetings or through teachers. The parents received two sets of questionnaires; both mothers and fathers were asked to individually complete the instrument. However, since both parents were not always available and participation in the study was voluntary, for some of the children, questionnaires were completed only by one parent. Parents returned completed questionnaires in sealed envelopes in a designated place at the school office, and the envelopes were subsequently collected by the person who conducted the study.

\section{Results}

Descriptive statistics for the APQ subscales are presented in Table 1. Confirmatory factor analysis was used to test a fivefactor statistical model, based on the a priori APQ subscales. The analysis was conducted using IBM SPSS Amos 22 (Arbuckle 2013), and it was applied separately to the samples of mothers and fathers. We used the maximum likelihood method, which is typically used for self-report questionnaires based on Likert scales (Kline 2011). We also used universally recognized fit indices to assess the fit of the five-factor model ( $\chi 2 / d f$ (Hoelter 1983), the Tucker-Lewis Index (TLI; Tucker

Table 1 Descriptive statistics and intercorrelations between the APQ subscales for mothers' and fathers' data

\begin{tabular}{|c|c|c|c|c|c|c|c|}
\hline & & M & SD & Inv & PP & PM & ID \\
\hline \multirow[t]{2}{*}{ Inv } & Mothers & 40.58 & 5.52 & - & & & \\
\hline & Fathers & 37.42 & 5.48 & - & & & \\
\hline \multirow[t]{2}{*}{ PP } & Mothers & 25.56 & 3.57 & $.663 * * *$ & & & \\
\hline & Fathers & 24.42 & 3.18 & $.666^{* * *}$ & & & \\
\hline \multirow[t]{2}{*}{ PM } & Mothers & 15.86 & 6.27 & $-.496 * * *$ & $-.413 * * *$ & & \\
\hline & Fathers & 15.40 & 4.25 & $-.370 * * *$ & $-.363 * * *$ & & \\
\hline \multirow[t]{2}{*}{ ID } & Mothers & 14.73 & 3.75 & $-.344 * * *$ & $-.238 * * *$ & $.468 * * *$ & \\
\hline & Fathers & 14.64 & 3.25 & $-.173 * * *$ & -.086 & $.338 * * *$ & \\
\hline \multirow[t]{2}{*}{$\mathrm{CP}$} & Mothers & 4.23 & 1.74 & $-.362 * * *$ & $-.247 * * *$ & $.317 * * *$ & $.392 * * *$ \\
\hline & Fathers & 4.08 & 1.49 & $-.152 * *$ & $-.110^{*}$ & $.223 * * *$ & $.314 * * *$ \\
\hline
\end{tabular}

Inv Involvement, $P P$ Positive Parenting, $P M$ Poor Monitoring, $I D$ Inconsistent Discipline, $C P$ Corporal Punishment

$* p<.05, * * p<.01, * * * p<.001$ 
and Lewis 1973), the comparative fit index (CFI; Bentler 1990, 1992), the root mean square error of approximation (RMSEA; Steiger 1990) and the standardized root mean square residual (SRMR; Jöreskog and Sörbom 1986). Hu and Bentler (1999) have suggested that $\chi^{2} / d f<3$, TLI and CFI $>.90$ (ideally $>.95$ ), RMSEA $<.08$ (ideally $<.05$ ) and SRMR $<.09$ indicate a good fit.

The CFA revealed that the five-factor model has a rather unsatisfactory fit (see Table 2, "raw" models): In particular, the values of $\chi^{2} / d f$ in mothers and the relative fit indices (CFI and TLI) in fathers indicated a far from excellent fit. However, an examination of modification indices (M.I.) provided by AMOS suggested that the fit of the tested models could be improved if some error terms were free to correlate, but did not suggest that any specific item should be reallocated. We decided to add covariances only for those pairs of items for which the values of M.I. were relatively high for both mothers and fathers. Moreover, we decided to limit number of freely correlated errors to only one per subscale. The revised models were based upon three modification indices of the greatest magnitude (ranked separately in fathers and mothers) and obviously included correlated errors only within the same subscales of APQ, as suggested by Byrne (2010). A deeper look at the items showed that each of the correlated item pairs was characterized by a similar wording or content. A detailed list of modification indices, along with the rationale and conceptual justification for adding each of them, is presented in the supplementary Table S1. Implementing the suggested changes (see Table 2, after M.I. $)$ improved fit in mothers $\left(\Delta \chi^{2}(3)=269.62, p<.001\right)$ and in fathers $\left(\Delta \chi^{2}(3)=78.943, p<.001\right)$. The fit indices of the improved models were acceptable, with two exceptions: TLI and CFI in the fathers' sample were at .82 and .84 , respectively, which is somewhat below the recommended threshold. Given that these thresholds are only intended as a general guideline (see Hu and Bentler 1999), we concluded that the CFA provided evidence that the Polish version of APQ has a five-factor structure. Factor loadings for particular items in the five-factor model are presented in Table 3.

To investigate the differences between mothers' and fathers' parenting practices, a comparison of parenting practices was made on a limited group of parents in which both parents of a given child completed the questionnaires. Participants of this group were 305 pairs of mothers and fathers of 146 boys and 159 girls in the age range of 6-13 years (mean age: 9.4 years) from 25 primary schools in the Mazovian district of Poland. The majority of children $(43 \%)$ were from a city area, $39 \%$ were from a town and $18 \%$ were from rural areas. The distribution of parents' level of education is similar as in the whole sample. The majority $(53 \%)$ of mothers reported having higher education, $33 \%$ secondary education, $11 \%$ vocational education and $3 \%$ primary education, whereas $37 \%$ of fathers reported having higher education, $39 \%$ secondary education, $21 \%$ vocational education and $3 \%$ primary education.

Basing on King and Minium's (2003) recommendation on assessing differences between matched groups, we used student's $t$ test for dependent samples (Table 4). Results revealed that mothers and fathers differed significantly in the two domains of positive parenting practices: Fathers reported lower parental involvement and less use of positive parenting than mothers. The effect size was large in the first case and medium in the second case. There were no significant differences between mothers and fathers on inconsistent discipline and corporal punishment. However, mothers had significantly lower scores on poor monitoring/supervision than did fathers; at the same time, this difference had a small effect size.

To assess the internal consistency of the APQ values, Cronbach's alpha was computed separately for mothers and fathers. Four of the APQ subscales had acceptable reliability. Alpha coefficients ranged from .75 to .86 for mothers and from .67 to .79 for fathers (Table 5). Only the inconsistent discipline subscale in the sample of fathers had an alpha coefficient below the acceptable level (.53). We also calculated inter-factor correlations (Table 1). Since scores of all of the APQ subscales were not normally distributed (Shapiro-Wilk test, $p<0.05$ ), nonparametric Spearman's rank correlations were conducted. There were strong positive correlations between the two APQ positive practices subscales for both mothers and fathers. The negative parenting subscales were also positively correlated with each other in both mothers and fathers. Inconsistent discipline and corporal punishment were uncorrelated or weakly correlated with positive practices subscales in the case of fathers. However, poor monitoring/ supervision was moderately negatively correlated with both positive parenting subscales. In the case of mothers, all the negative practices subscales were negatively correlated with the positive practices subscales.
Table 2 Fit indices for the hypothesized five-factor model in mothers and fathers sample before and after modifications based on modification indices

\begin{tabular}{llllllll}
\hline & $\chi \mathrm{b}$ & $\mathrm{df}$ & $\chi$ fefo & TLI & CFI & RMSEA & SRMR \\
\hline Mothers - raw model & 2078.126 & 550 & 3.778 & .88 & .89 & .06 & .05 \\
Mothers - after M.I. & 1808.506 & 547 & 3.306 & .90 & .91 & .05 & .04 \\
Fathers - raw model & 1324.605 & 550 & 2.408 & .80 & .82 & .05 & .05 \\
Fathers - after M.I. & 1245.662 & 547 & 2.277 & .82 & .84 & .05 & .05 \\
\hline
\end{tabular}

M.I. modification indices 
Table 3 Standardized factor loadings, based on maximum likelihood estimation, for the hypothesized five-factor model of mothers' and fathers' parenting practices

\begin{tabular}{|c|c|c|c|c|c|c|c|c|c|c|}
\hline \multirow[b]{2}{*}{ Item } & \multicolumn{5}{|c|}{ Mothers } & \multicolumn{5}{|c|}{ Fathers } \\
\hline & INV & PP & PM & ID & $\mathrm{CP}$ & INV & $\mathrm{PP}$ & PM & ID & $\mathrm{CP}$ \\
\hline 1. You have a friendly talk with your child. & .76 & & & & & .58 & & & & \\
\hline 4. You volunteer to help with special activities that your child is involved in. & .55 & & & & & .54 & & & & \\
\hline 7. You play games or do other fun things with your child. & .63 & & & & & .52 & & & & \\
\hline 9. You ask your child about his/her day in school. & .71 & & & & & .64 & & & & \\
\hline 11. You help your child with his/her homework. & .34 & & & & & .45 & & & & \\
\hline 14. You ask your child what his/her plans are for the coming day. & .58 & & & & & .64 & & & & \\
\hline 15. You drive your child to a special activity. & .44 & & & & & .45 & & & & \\
\hline 20. You talk to your child about his/her friends. & .69 & & & & & .66 & & & & \\
\hline 23. Your child helps plan family activities. & .52 & & & & & .46 & & & & \\
\hline 26. You attend PTA meetings, parent/teacher conferences, or other meetings at your child's school. & .47 & & & & & .43 & & & & \\
\hline 2. You let your child know when he/she is doing a good job with something. & & .75 & & & & & .64 & & & \\
\hline 5. You reward or give something extra to your child for obeying you or behaving well. & & .27 & & & & & .17 & & & \\
\hline 13. You compliment your child when he/she does something well. & & .82 & & & & & .77 & & & \\
\hline 16. You praise your child if he/she behaves well. & & .77 & & & & & .74 & & & \\
\hline 18. You hug or kiss your child when he/she has done something well. & & .72 & & & & & .68 & & & \\
\hline 27. You tell your child that you like it when he/she helps around the house. & & .71 & & & & & .63 & & & \\
\hline 6. Your child fails to leave a note or let you know where he/she is going. & & & .70 & & & & & .48 & & \\
\hline 10. Your child stays out in the evening past the time he/she is supposed to be home. & & & .81 & & & & & .51 & & \\
\hline 17. Your child is out with friends you don't know. & & & .69 & & & & & .60 & & \\
\hline 19. Your child goes out without a set time to be home. & & & .82 & & & & & .65 & & \\
\hline 21. Your child is out after dark without an adult with $\mathrm{him} / \mathrm{her}$. & & & .80 & & & & & .49 & & \\
\hline 24. You get so busy that you forget where your child is and what he/she is doing. & & & .72 & & & & & .53 & & \\
\hline 28. You don't check that your child comes home at the time she/he was supposed to. & & & .39 & & & & & .27 & & \\
\hline 29. You don't tell your child where you are going. & & & .36 & & & & & .34 & & \\
\hline 30. Your child comes home from school more than an hour past the time you expect him/her. & & & .71 & & & & & .47 & & \\
\hline 32. Your child is at home without adult supervision. & & & .44 & & & & & .39 & & \\
\hline 3. You threaten to punish your child and then do not actually punish him/her. & & & & .40 & & & & & .38 & \\
\hline 8. Your child talks you out of being punished after he/she has done something wrong. & & & & .33 & & & & & .32 & \\
\hline 12. You feel that getting your child to obey you is more trouble than it's worth. & & & & .58 & & & & & .34 & \\
\hline $\begin{array}{l}\text { 22. You let your child out of a punishment early (like lift restrictions earlier than you originally } \\
\text { said). }\end{array}$ & & & & .44 & & & & & .18 & \\
\hline 25. Your child is not punished when he/she has done something wrong. & & & & .31 & & & & & .19 & \\
\hline 31. The punishment you give your child depends on your mood. & & & & .65 & & & & & .59 & \\
\hline 33. You spank your child with your hand when he/she has done something wrong. & & & & & .73 & & & & & .72 \\
\hline 35. You slap your child when he/she has done something wrong. & & & & & .78 & & & & & .70 \\
\hline 38. You hit your child with a belt, switch, or other object when she/he has done something wrong & & & & & .66 & & & & & .54 \\
\hline
\end{tabular}

Inv Involvement, $P P$ Positive Parenting, $P M$ Poor Monitoring, ID Inconsistent Discipline, $C P$ Corporal Punishment

\section{Discussion}

Our results showed that the five-factor model of the APQ is characterized by a good fit in the sample of Polish mothers. However, inspection of the goodness-of-fit indices in the sample of fathers demonstrated ambiguous results: Two of the model fit indices revealed good or very good model fit, whereas two others were slightly below the recommended threshold.
Fathers have been shown to play a different role in childrearing than mothers in most families. They serve a particularly important function, among others, in supporting a child's exploration and independence building (Grossmann et al. 2002; Paquette 2004). Comparison of mothers' and fathers' parenting practices also revealed differences between parents in certain parenting domains. These results are consistent with previous findings (Gryczkowski et al. 2010) 
Table 4 Means, standard deviations and comparisons between mothers' and fathers' APQ scores ( $N=305$ pairs)

\begin{tabular}{|c|c|c|c|c|c|c|c|}
\hline & \multicolumn{2}{|c|}{ Mothers } & \multicolumn{2}{|c|}{ Fathers } & \multirow[b]{2}{*}{$t$} & \multirow[b]{2}{*}{$p$} & \multirow[b]{2}{*}{$E S$} \\
\hline & $M$ & $S D$ & $M$ & $S D$ & & & \\
\hline Involvement & 41.59 & 4.11 & 37.19 & 5.42 & 13.13 & $<.001$ & .91 \\
\hline Positive parenting & 26.41 & 2.59 & 24.49 & 3.03 & 10.06 & $<.001$ & .68 \\
\hline Poor monitoring & 13.94 & 4.03 & 15.18 & 4.13 & -6.28 & $<.001$ & .30 \\
\hline Inconsistent discipline & 14.28 & 3.63 & 14.61 & 3.33 & -1.69 & .092 & .10 \\
\hline Corporal punishment & 4.06 & 1.32 & 4.08 & 1.51 & -.17 & .868 & .01 \\
\hline
\end{tabular}

Effect size (ES) was estimated according to the $t_{c}$ formula endorsed by Dunlap et al. (1996). Simulations showed that this was the least distorted estimator of $d$ in data from matched groups

indicating that mothers are more involved and willing to provide positive reinforcement to their children; they are also characterized by lower levels of poor monitoring than are fathers. Differences obtained in the present study could also reflect the typical structure and organization of daily life in Polish families, as currently affected by the political, economic, cultural and social transformations taking place in postcommunist countries. Although there has been movement in the Polish society towards the individualism and independence characteristic of Western cultures, the family remains the most important value in Poland (Harkness et al. 2011; Kmita 2016). Altogether, a collectivistic orientation promoting interdependence and traditional family relationships coexists alongside the emerging individualistic view. Therefore, Polish mothers are usually closer to their children than are fathers; even when involved in professional careers, their role in home care and childrearing is still greater than that of fathers. Polish mothers are also characterized by high levels of control in contrast to mothers from other Western countries (Dwairy and Achoui 2010). Against this background, it could be that the APQ less precisely captures the specificity of parenting behaviors of fathers than those of mothers. This topic should be further explored in future studies conducted in large samples of fathers and mothers form various countries and cultures. Our results, showing a good fit of the five-factor model of the Parent Global Report version of the APQ in the

Table 5 Values of Cronbach's alpha for the APQ subscales

\begin{tabular}{lll}
\hline & Cronbach's alpha Maternal data & Cronbach's alpha Paternal data \\
\hline Inv & .822 & .794 \\
PP & .815 & .745 \\
PM & .860 & .700 \\
ID & .666 & .532 \\
CP & .751 & .670
\end{tabular}

Inv Involvement, $P P$ Positive Parenting, $P M$ Poor Monitoring, $I D$ Inconsistent Discipline, $C P$ Corporal Punishment sample of Polish parents (especially with respect to mothers) are consistent with Frick's (1991; Shelton et al. 1996) model of parenting practices.

Four of the APQ subscales (involvement, positive parenting, poor monitoring/supervision and corporal punishment) were characterized by acceptable or high internal consistency in both the mother's and father's samples (with Cronbach's alphas ranging from 0.67 to 0.86 ). The items included in these subscales also loaded on the target factors at a level greater than 0.3 , with the exception of one positive parenting item: "You reward your child or give him or her something extra for obeying or behaving well." This is the only item of this subscale that refers to material reward, not praise or encouragement; therefore, this result suggests that parents may use material rewards in a different way from other kinds of positive reinforcement. The inconsistent discipline subscale had the lowest internal consistency: In the fathers' data, its alpha coefficient was below the threshold for reliability (0.53), which is in line with some previous studies (Essau et al. 2006). In addition, most of the items on this subscale also had low factor loadings. Only one item ("The punishment you give your child depends on your mood") loaded highly in both mother's and father's data. We assume that this item reflects the essence of inconsistent discipline, i.e. the lack of connection between the parent's actions and the child's behavior. Low factor loadings of the other items may be related, not only to inconsistent discipline, but also to the flexibility of the parent (Item 22) or the tendency to use parenting methods other than punishment (Item 25).

\section{Study 2}

The aim of this study was to explore the construct validity of the Polish Parent Global Report version of the APQ by investigating associations between parenting practices and a child's ADHD and oppositional-defiant symptoms (reported by parents separately in a group of mothers and a group of fathers).

\section{Method}

\section{Participants}

Questionnaires were completed by 295 mothers and $189 \mathrm{fa}-$ thers of 316 children ( 149 boys and 167 girls) in the age range of 7-12 years (mean age: 9.5 years) from the 12 primary schools in the Mazovian district of Poland. The sampling technique was the same as in the Study 1 . Of the mothers, $75 \%$ reported having higher education, $20 \%$ secondary education, $3.5 \%$ vocational education and $1.5 \%$ primary education, whereas $53 \%$ of fathers reported having higher education, $34 \%$ secondary education, $11 \%$ vocational education and $2 \%$ primary education. The majority of children $(70 \%)$ were 
from a city area, $24 \%$ were from a town, and $6 \%$ were from rural areas. In most of the families $(77 \%)$ that took part in the study, the income per family member is higher than the national average.

\section{Measures}

APQ (see Method Section in Study 1)

The Rating Scales for Parents The Rating Scales for Parents (Gambin and Święcicka 2015, 2016) were constructed at the University of Warsaw. Authors used an empirically-based, bottom-up approach (Achenbach et al. 2003), which involved not making any initial assumptions about the existence of specific diagnostic categories. The items included in the initial version of the scale were based, not on the ADHD diagnostic manual, but on teachers' and parents' descriptions of children's hyperactivity-impulsivity and inattention symptoms. The Rating Scale for Parents comprises 22 items and is organized into two subscales, extracted through factor analysis. The hyperactivity-impulsivity subscale (11 items, $\alpha=.90$ ) measures the intensity of impulsive and hyperactive behaviors (e.g. "It is difficult for him/her to sit in one place”). It also includes items describing a lack of emotional control, which were included in this subscale on the basis of exploratory factor analysis. The inattention subscale (11 items, $\alpha=.92$ ) assesses the child's tendencies to become distracted, to tire quickly of mental activities, to withdraw attention, and to be careless (e.g. "He/she forgets his/her homework or what the teacher asked"). The parent is asked to indicate the extent to which each item applies to his or her child, using a 4-point scale ( 1 = not true, 2 = somewhat true; 3 = fairly true; 4 = definitely true). Previous studies conducted in Poland (Gambin and Święcicka 2015, 2016) show that the scale has good convergent and discriminant validity.

Children's ODD Symptoms Rating Scale for Parents Children's ODD Symptoms Rating Scale for Parents was constructed at the University of Warsaw and is based on the ODD criterion symptoms included in the Diagnostic and Statistical Manual of Mental Disorders (4th ed.; American Psychiatric Association 1994). The instrument consists of 13 items. Parents assessed the severity of the child's symptoms using a 4-point scale, as in the Rating Scale for Parents. Internal reliability for this measure was very good in the groups of mothers $(\alpha=.93)$ and fathers $(\alpha=.93)$.

\section{Procedure}

The procedure of the study was the same as in Study 1 .

\section{Results}

Descriptive statistics are presented in Table 6. Results of correlations between the APQ subscales and the intensity of children's hyperactivity-impulsivity, inattention and ODD in the sample of mothers and fathers, are presented in Table 7. The strength and direction of correlations were similar in groups of mothers and fathers, and consistent with all our hypotheses. In general, negative correlations were found between ADHD and ODD symptoms and positive parenting practices (positive parenting and involvement), whereas positive correlations were found between a child's psychopathological symptoms and negative parenting practices (poor monitoring/supervision, inconsistent discipline and corporal punishment). Consistently with the hypothesis H1 child's ODD symptoms were correlated with all the dimensions of parenting practices in a group of mothers and with almost all (apart from positive parenting) parenting practices in a group of fathers. In line with the hypothesis H2, ADHD symptoms, especially the hyperactivityimpulsivity domain, were the most strongly correlated with inconsistent discipline in a sample of both mothers and fathers. Moreover, in accordance with hypothesis $\mathrm{H} 3$ relations between a child's symptoms and negative parenting practices were stronger than those between a child's symptoms and positive parenting.

\section{Discussion}

All associations between parenting practices and ODD and ADHD symptoms are consistent with our hypotheses indicating that the subscales of the Polish version of the APQ relate to measures of other constructs in theoretically predictable ways

Table 6 Descriptive statistics for the APQ subscales, ADHD and ODD symptoms for mothers' and fathers' data for Study 2

\begin{tabular}{|c|c|c|c|c|}
\hline & \multicolumn{2}{|c|}{ Mothers } & \multicolumn{2}{|c|}{ Fathers } \\
\hline & M & SD & M & SD \\
\hline Inv & 41.28 & 3.99 & 37.39 & 5.29 \\
\hline PP & 25.50 & 2.75 & 24.06 & 3.14 \\
\hline PM & 13.98 & 3.82 & 15.06 & 3.98 \\
\hline ID & 13.73 & 3.83 & 14.28 & 3.99 \\
\hline $\mathrm{CP}$ & 3.28 & 1.18 & 3.99 & 1.47 \\
\hline Inat & 24.85 & 6.73 & 25.46 & 6.47 \\
\hline $\mathrm{H} / \mathrm{Im}$ & 25.61 & 6.65 & 26.03 & 6.24 \\
\hline ODD & 23.54 & 7.56 & 24.12 & 7.52 \\
\hline
\end{tabular}

Inv Involvement, $P P$ Positive Parenting, $P M$ Poor Monitoring, ID Inconsistent Discipline, $C P$ Corporal Punishment, Inat Inattention, $H / I m$ Hyperactivity/Impulsivity, $O D D$ Oppositional-Defiant Disorder Symptoms 
Table 7 Spearman's correlations between the APQ subscales and children's inattention, hyperactivity/impulsivity and oppositional-defiant disorder symptoms

\begin{tabular}{lllllll}
\hline & & In. & PP & PM & ID & CP \\
\hline Mothers & Inat & $-.236 * *$ & $-.126 *$ & $.141 *$ & $.289 * *$ & $.215^{* *}$ \\
& $\mathrm{H} / \mathrm{Im}$ & $-.155^{* *}$ & -.069 & $.197 * *$ & $.391 * *$ & $.264 * *$ \\
& ODD & $-.229 * *$ & $-.131^{*}$ & $.243 * *$ & $.421 * *$ & $.336 * *$ \\
Fathers & Inatt & $-.198^{* *}$ & .041 & $.228 * *$ & $.252^{* *}$ & $.263 * *$ \\
& $\mathrm{H} / \mathrm{Im}$ & -.112 & .032 & $.159 *$ & $.396 * *$ & $.235^{* *}$ \\
& ODD & $-.236^{* *}$ & -.079 & $.202 * *$ & $.406 * *$ & $.285^{* *}$ \\
\hline
\end{tabular}

Inat Inattention, H/Im Hyperactivity/Impulsivity, $O D D$ OppositionalDefiant Disorder Symptoms, Inv Involvement, PP Positive Parenting, $P M$ Poor Monitoring, $I D$ Inconsistent Discipline, $C P$ Corporal Punishment

$* p<.05, * * p<.01$

and thus confirming that the questionnaire has a good construct validity. Hyperactivity-impulsivity symptoms were most strongly associated with inconsistent discipline in both the mothers' and fathers' samples as predicted by the hypothesis H2. This result is in line with previous findings and theoretical models that describe the bidirectional relationship between hyperactivity-impulsivity symptoms and inconsistent discipline that leads to the exacerbation of ADHD symptoms. As noted earlier, this association seems to be very complex and moderated by the following factors in particular: parentdriven effects (e.g. parental ADHD symptoms, other parental psychopathology symptoms, parental difficult temperament); and child-driven effects (e.g. genetic vulnerabilities toward hyperactivity-impulsivity, difficult temperament; Hawes et al. 2013; Martel et al. 2011, 2012; Nigg et al. 2010; Sonuga-Barke et al. 2009; Ullsperger et al. 2016). We also found that oppositional-defiant symptoms were most strongly associated with inconsistent discipline; however, they were also strongly correlated with other negative parenting practices, such as poor monitoring/supervision and corporal punishment than were ADHD symptoms, thus supporting the hypothesis $\mathrm{H} 1$. This pattern of results seems to be in line with theoretical models and findings showing that childparent relations of children with elevated levels of hyperactivity-impulsivity, as well as in the presence of various negative factors (such as parental antisocial traits, marital conflict, poor parenting skills), start to be characterized by negatively escalating cycles: In response to a child's noncompliance and hyperactive behaviors, parents start to use more and more negative parenting practices, which leads to an exacerbation of a child's disruptive problems (Martel et al. 2011, 2012; Patterson et al. 2000). Thus, in line with hypotheses H1 and $\mathrm{H} 2$, hyperactivity-impulsivity symptoms are most strongly related to inconsistent discipline, whereas ODD symptoms are associated more strongly than ADHD symptoms with all of the negative parenting practices.
Moreover, consistent with hypothesis H3, negative parenting practices were more strongly related to child behavior problems than positive parenting practices. In addition, involvement was more strongly associated with ADHD and ODD symptoms than positive parenting (use of reinforcement). There was a very low correlation in the mother's sample, and no significant correlation in the father's sample, between the use of positive reinforcement and ADHD and ODD symptoms. These results support previous findings (e.g. Ellis and Nigg 2009) that demonstrate a very weak or no relationship between the use of positive reinforcement and a child's disruptive behavior problems, and are in line with evidence indicating differential relations between mothers' and fathers' parenting and children's disruptive behavior problems (Gryczkowski et al. 2010). It could be that effectiveness of the use of reinforcement as a parenting method depends on various factors, such as parental attitudes and beliefs concerning childrearing and their repertoire of parenting tools and skills, as well as various characteristics of the child (Henderlong and Lepper 2002). Thus, it would be important to look for moderators of associations between a child's disruptive symptoms and various positive parenting practices. Further, the subscale of the APQ concerning positive reinforcement does not measure the frequency of the use of positive reinforcement, but it does assess how often parents reinforce their children when they behave well. It could be that parents rarely notice positive behaviors in their children with ADHD and ODD symptoms and, in effect, rarely use positive reinforcement. Therefore, it would be valuable to investigate the relations between disruptive behaviors and positive parenting practices using various assessment methods (such as observation, questionnaires and interviews) in future studies.

Overall, associations between parenting practices and children's behavior problems are in line with all of our hypotheses and thus confirm that the Polish version of the APQ has good construct validity.

\section{General Discussion and Conclusions}

Parenting practices play a key role in a child's socialization, as well as in development and maintenance of externalizing disorder symptoms. Therefore, it is important to reliably measure this construct in a range of countries and cultures to compare findings on a child's adjustment and to investigate the mechanisms of change in child and adolescent therapy programs. A popular measure used to assess parenting practices is the Alabama Parenting Questionnaire (APQ). However, to the best of our knowledge, none of the previous studies have verified the five-factor structure of this instrument using confirmatory factor analysis (CFA), which allows researchers to investigate whether the data fit a hypothesized measurement model based on theory or/and previous research. 
Our study is the first to verify the five-factor structure of the Parent Global Report version of the APQ using confirmatory factor analysis. Moreover, we have examined construct validity of the Polish version of the APQ by investigating if parenting practices are related to child's ADHD and ODD symptoms (as reported by parents) in accordance with theories and previous studies. In general, our data indicate that the questionnaire has a good construct validity and confirm the five-factor structure of the APQ, however, the model fit was better for mothers than for fathers, which could result from different specificity of parenting behaviors displayed by the fathers in contrast to those of the mothers. These differences, although in line with previous studies, could also be associated with characteristics unique to Poland, in that the society continues to undergo a process of transformation resulting in the merging and coexistence of collectivistic and individualistic orientations - not only in the society as a whole, but also at the level of the family (Kmita 2016). Moreover, our study shows that despite cultural and social differences, association patterns between parenting practices and ODD and ADHD symptoms in our sample were similar to those in North American and Western European samples. Our findings are also consistent with the theoretical models (Martel et al. 2012; Stormshak et al. 2000) that emphasize the role of parenting practices in the development of ADHD and ODD symptoms and describe complex nature of relations between parenting and externalizing symptoms in children. These associations are influenced by genotype-environment correlations, parent-driven and child-driven effects, as well as by coercive developmental sequences of negative parent-child interactions that lead to increase in negative parenting practices and disruptive behavior problems in children (Burke et al. 2008; Martel et al. 2011; Martel et al. 2012; Nigg et al. 2010; Patterson 1982, 2002; Sonuga-Barke et al. 2009; Ullsperger et al. 2016).

Obtained differences between the parents in some parenting practices, as well as the differential relations between mothers' and fathers' parenting and children's externalizing behavior problems, are also in line with previous findings demonstrating differences in maternal and paternal parenting (Ellis and Nigg 2009; Gryczkowski et al. 2010). The mothers reported stronger involvement with the children than the fathers. They also declared to use positive practices more often and to better monitor their children in comparison with the fathers. Also, the use of positive reinforcement was significantly associated with the symptoms of ADHD and ODD only in the mothers, and not the fathers. There were no significant differences between the parents in the declared level of inconsistent discipline and corporal punishment, and all types of negative parenting practices of both mothers and fathers were associated with the symptoms of ADHD and ODD symptoms.

Our results indicate that theories and recommendations developed based on findings from North American and Western European samples may be applied to parents and children from other countries (in this case, from Poland). In particular, it can be expected that therapeutic interventions focused on the modification of parenting methods developed in United States (e.g. Gardner and Leijten 2017) may be effective in the treatment of children with aggressive, oppositional and hyperactive behaviors in Poland. The Polish version of the APQ will allow researchers to test the effectiveness of such interventions and explore the developmental sequences of relations between parenting practices and child behaviors in longitudinal studies in Poland.

Our study has some limitations that should be noted. Firstly, there is a discrepancy between the sizes of the paternal and maternal samples: The fathers sample is smaller than the mothers sample. Secondly, since we used only the Parent Global Report version of the APQ, our results should not be generalized to the other versions of the APQ. Moreover, it would be valuable to investigate relations between results of the Parent Global Report version of the APQ and parenting practices assessed with other methods, such as the Child Global Report version of the APQ, interviews with parents and observations of parent-child interaction, as well as explore associations with various spheres of a child's functioning (e.g. emotional and social functioning). Another limitation is that our study was conducted only in the schools from Mazovian district, using convenience sampling as opposed to stratified randomized sampling, which would have increased our confidence in the generalization of the findings. Finally, the child's ODD and ADHD symptoms were rated only by the parents. Since the relationship between specific practices undertaken by the parents and an individual child's behaviors are reciprocal, we may predict that there will be a stronger convergence between the parenting practices and parent's assessment of child's behavior than between those practices and teacher's ratings of a child's behavior. Thus, it would be worth also including a teacher's report of a child's ADHD and ODD symptoms in further studies. This would enable us to gain a deeper understanding of the associations between parenting practices and the child's behaviors, as observed by various informants. As well, future studies should further investigate and verify the factor structure of the APQ and test theoretical models that emphasize the role of parenting practices in the development of disruptive behaviors in children across various countries and cultures. 
Funding This project was supported by the Polish National Science Center - grant number 2012/07/B/HS6/01469.

\section{Compliance with Ethical Standards}

Ethical Approval All procedures performed in studies involving human participants were in accordance with the ethical standards of the University of Warsaw Institutional Review Board and with the 1964 Helsinki declaration and its later amendments or comparable ethical standards.

Informed Consent Informed consent was obtained from all individual participants included in the study.

Conflict of Interest The authors declare that they have no conflict of interest.

Open Access This article is distributed under the terms of the Creative Commons Attribution 4.0 International License (http:// creativecommons.org/licenses/by/4.0/), which permits unrestricted use, distribution, and reproduction in any medium, provided you give appropriate credit to the original author(s) and the source, provide a link to the Creative Commons license, and indicate if changes were made.

\section{References}

Achenbach, T. M., Dumenci, L., \& Rescorla, L. A. (2003). DSM-oriented and empirically based approaches to constructing scales from the same item pools. Journal of Clinical Child and Adolescent Psychology, 32(3), 328-340.

Amato, P. R., \& Fowler, F. (2002). Parenting practices, child adjustment, and family diversity. Journal of Marriage and Family, 64(3), 703716.

American Psychiatric Association. (1994). Diagnostic and statistical manual of mental disorders (4th ed.). Washington, DC: Author.

Arbuckle, J. L. (2013). IBM SPSS Amos 22 user's guide. Mount Pleasant: Amos Development Corporation.

Bentler, P. M. (1990). Comparative fit indexes in structural equation models. Psychological Bulletin, 107, 238-246.

Bentler, P. M. (1992). On the fit to models to covariances and methodology to the bulletin. Psychological Bulletin, 112, 400-404.

Bøe, T., Sivertsen, B., Heiervang,E., Goodman, R., Lundervold, A. J., \& Hysing, M. (2014). Socioeconomic status and child mental health: The role of parental emotional well-being and parenting practices. Journal of Abnormal Child Psychology, 42, 705-715.

Bögels, S., \& Phares, V. (2008). Fathers' role in the etiology, prevention and treatment of child anxiety: A review and new model. Clinical Psychology Review, 28, 539-558.

Brislin, R. W. (1970). Back-translation for cross-cultural research. Journal of Cross-Cultural Psychology, 1(3), 185-216.

Burke, J. D., Pardini, D. A., \& Loeber, R. (2008). Reciprocal relationships between parenting behavior and disruptive psychopathology from childhood through adolescence. Journal of Abnormal Child Psychology, 36, 679-692.

Byrne, B. M. (2010). Structural equation modeling with AMOS: Basic concepts, applications, and programming (2nd ed.). Abingdon: Routledge Taylor \& Francis.

Chronis, A. M., Lahey, B. B., Pelham, W. E., Williams, S. H., Baumann, B. L., Kipp, H., Jones, H. A., \& Rathouz, P. J. (2007). Maternal depression and early positive parenting predict future conduct problems in young children with attention-deficit/hyperactivity disorder. Developmental Psychology, 43, 70-82.

Chronis-Tuscano, A., O’Brien, K. A., Johnston, C., Jones, H. A., Clarke, T. L., Raggi, V. L., Rooney, M. E., Diaz, Y., Pian, J., \& Seymour, K. E. (2011). The relation between maternal ADHD symptoms \& improvement in child behavior following brief behavioral parent training is mediated by change in negative parenting. Journal of Abnormal Child Psychology, 39(7), 1047-1057.

Cicchetti, D. (2006). Development and psychopathology. In W. D. Cicchetti \& D. J. Cohen (Eds.), Developmental psychopathology (Vol. 1, pp. 1-13). Hoboken: Wiley.

Clerkin, S. M., Marks, D. J., Policaro, K. L., \& Halperin, J. M. (2007). Psychometric properties of the Alabama parenting questionnairepreschool revision. Journal of Clinical Child and Adolescent Psychology, 36, 19-28.

Cronbach, L. J., \& Meehl, P. E. (1955). Construct validity in psychological tests. Psychological Bulletin, 52, 281-302.

Dadds, M. R., Maujean, A., \& Fraser, J. A. (2003). Parenting and conduct problems in children: Australian data and psychometric properties of Alabama parenting questionnaire. Australian Psychologist, 38(3), $238-241$.

Darling, N., \& Steinberg, L. (1993). Parenting style as context: An integrative model. Psychological Bulletin, 113(3), 487-496.

de la Olsa, N., Granero, R., Penelo, E., Domènech, J. M., \& Ezpeleta, L. (2014). Psychometric properties of the Alabama parenting questionnaire-preschool revision (APQ-Pr) in 3 year-old Spanish preschoolers. Journal of Child and Family Studies, 23, 776-784.

De Los Reyes, A., \& Kazdin, A. E. (2005). Informant discrepancies in the assessment of childhood psychopathology: A critical review, theoretical framework, and recommendations for further study. Psychological Bulletin, 131(4), 483-509.

Dunlap, W. P., Cortina, J. M., Vaslow, J. B., \& Burke, M. J. (1996). Metaanalysis of experiments with matched groups or repeated measures designs. Psychological Methods, 1(2), 170-177.

Dwairy, M., \& Achoui, M. (2010). Parental control: A second crosscultural research on parenting, culture, and psychological adjustment of children. Journal of Child and Family Studies, 19, 16-22.

Earth, S. A., El-Sheikh, M., \& Cummings, E. (2009). Harsh parenting and child externalizing behavior: Skin conductance level reactivity as a moderator. Child Development, 80, 578-592.

Ellis, B., \& Nigg, J. (2009). Parenting practices and attention-deficit/hyperactivity disorder: Partial specificity of effects. Journal of the American Academy of Child and Adolescent Psychiatry, 48, 146154.

Esposito, A., Servera, M., Garcia-Banda, G., \& Del Giudice, E. (2016). Factor analysis of the Italian version of the Alabama parenting questionnaire in a community sample. Journal of Child and Family Studies, 25(4), 1208-1217.

Essau, C. A., Sasagawa, S., \& Frick, P. J. (2006). Psychometric properties of the Alabama parenting questionnaire. Journal of Child and Family Studies, 15(5), 595-614.

Faraone, S. V., Biederman, J., \& Milberger, S. (1995). How reliable are maternal reports of their children's psychopathology? One-year recall of psychiatric diagnoses of ADHD children. Journal of the American Academy of Child \& Adolescent Psychiatry, 34(8), 1001-1008.

Feinfield, K. A., \& Baker, B. L. (2004). Empirical support for a treatment program for families of young children with externalizing problems. Journal of Clinical Child and Adolescent Psychology, 33(1), 182195.

Frick, P. J. (1991). The Alabama parenting questionnaire. Tuscaloosa: Unpublished rating scale, University of Alabama.

Frick, P. J., Christian, R. E., \& Wootton, J. M. (1999). Age trends in the association between parenting practices and conduct problems. Behavior Modification, 23(1), 106-128. 
Gambin, M., \& Święcicka, M. (2015). Relationships of self-efficacy beliefs to executive functions, hyperactivity-impulsivity and inattention in school-aged children. Polish Journal of Applied Psychology, $13,33-42$.

Gambin, M., \& Święcicka, M. (2016). Heterogeneity in clinical symptoms and cognitive functioning of children with hyperactivityimpulsivity and inattention: Dimensional and person-centered perspectives. Polish Psychological Bulletin, 47, 195-206.

Gardner, F., \& Leijten, P. (2017). Incredible years parenting interventions: Current effectiveness research and future directions. Current Opinion in Psychology, 15, 99-104.

Gershoff, E. T., Grogan-Kaylor, A., Lansford, J. E., Chang, L., Zelli, A., Deater-Deckard, K., \& Dodge, K. A. (2010). Parent discipline practices in an international sample: Associations with child behaviors and moderation by perceived normativeness. Child Development, 81(2), 487-502.

Grossmann, K., Grossman, K. E., Fremmer-Bombik, E., Kindler, H., \& Scheuerer-Englisch, H. (2002). The uniqueness of the child-father attachment relationship: Fathers' sensitive and challenging play as pivotal variable in 16-year longitudinal study. Social Development, 11, 301-337.

Gryczkowski, M. R., Jordan, S. S., \& Mercer, S. H. (2010). Differential relations between mothers' and fathers' parenting practices and child externalizing behavior. Journal of Child and Family Studies, 19, 539-546.

Harkness, S., Zylicz, P. O., Super, C. M., Welles-Nyström, B., Ríos Bermúdez, M., Bonichini, S., et al. (2011). Children's activities and their meanings for parents: A mixed-methods study in six western cultures. Journal of Family Psychology, 25(6), 799-813.

Hawes, D. J., \& Dadds, M. R. (2006). Assessing parenting practices through parent-report and direct observation during parent-training. Journal of Child and Family Studies, 15, 554-567.

Hawes, D. J., Dadds, M. R., Frost, A. D. J., \& Russell, A. (2013). Parenting practices and prospective levels of hyperactivity/ inattention across early- and middle-childhood. Journal of Psychopathology and Behavioral Assessment, 35, 273-282.

Henderlong, J., \& Lepper, M. R. (2002). The effects of praise on children's intrinsic motivation: A review and synthesis. Psychological Bulletin, 128, 774-795.

Hinshaw, S. P., Owens, E. B., Wells, K. C., Kraemer, H. C., Abikoff, H. B., Arnold, L. E Arnold L. E., Conners C. K., Elliott G., Greenhill L. L., Hechtman L., Hoza B., Jensen P. S., March J. S., Newcorn J. H., Pelham W. E., Swanson J. M., Vitiello B. Wigal, T. (2000). Family processes and treatment outcome in MTA: Negative/ineffective parenting practices in relation to multimodal treatment. Journal of Abnormal Child Psychology, 28(6), 555-568.

Hoelter, J. W. (1983). The analysis of covariance structures: Goodness of fit indices. Sociological Methods \& Research, 11, 325-344.

Hu, L., \& Bentler, P. M. (1999). Cutoff criteria for fit indexes in covariance structure analysis: Conventional criteria versus new alternatives. Structural Equation Modeling, 6, 1-55.

Hurley, K. D., Huscroft-D’Angelo, J., Trout, A., Griffith, A., \& Epstein, M. (2014). Assessing parenting skills and attitudes: A review of the psychometrics of parenting measures. Journal of Child and Family Studies, 23, 812-823.

Johnston, C., \& Mash, E. J. (2001). Families of children with attentiondeficit/hyperactivity disorder: Review and recommendations for future research. Clinical Child and Family Psychology Review, 4(3), 183-207.

Jöreskog, K. G., \& Sörbom, D. (1986). LISREL VI: Analysis of linear structural relationships by maximum likelihood and least squares methods. Mooresville: Scientific Software.

King, B. M., \& Minium, E. W. (2003). Statistical reasoning in psychology and education. Hoboken: John Wiley \& Sons.
Kline, R. B. (2011). Principles and practice of structural equation modeling. Methodology in the social sciences (3rd ed.). New York: Guilford Press.

Kmita, G. (2016). Parenting beliefs and practices in Poland. In G. Nicolas, A. Bejarano, \& D. Lee (Eds.), Contemporary parenting (pp. 142-155). New York: Routledge.

Li, J. J., \& Lee, S. S. (2012). Association of positive and negative parenting behavior with childhood ADHD: Interactions with offspring monoamine oxidase a (MAO-A) genotype. Journal of Abnormal Child Psychology, 40, 165-175.

Locke, L. M., \& Prinz, R. J. (2002). Measurement of parental discipline and nurturance. Clinical Psychology Review, 22, 895-929.

Marcus, D. K., \& Barry, T. D. (2011). Does attention-deficit/hyperactivity disorder have a dimensional latent structure? A taxometric analysis. Journal of Abnormal Psychology, 120(2), 427-442.

Martel, M. M., Nikolas, M., Jernigan, K., Friderici, K., Waldmann, I., \& Nigg, J. T. (2011). The dopamine receptor D4 gene (DRD4) gene moderates family environmental effects on ADHD. Journal of Abnormal Child Psychology, 39, 1-10.

Martel, M. M., Nikolas, M., Jernigan, K., Friderici, K., \& Nigg, J. T. (2012). Diversity in pathways to common childhood disruptive behavior disorders. Journal of Abnormal Child Psychology, 40, 1223 1236.

Molinuevo, B., Pardo, Y., \& Torrubia, R. (2011). Psychometric analysis of the Catalan version of the Alabama parenting questionnaire (APQ) in a community sample. Spanish Journal of Psychology, 14, 944-955.

Nigg, J., Nikolas, M., \& Burt, S. A. (2010). Measured gene by environment interaction in relation to attention-deficit/hyperactivity disorder (ADHD). Journal of the American Academy of Child and Adolescent Psychiatry, 49, 863-873.

Nikolas, M. A., \& Burt, S. A. (2010). Genetic and environmental influences on ADHD symptom dimensions of inattention and hyperactivity: A meta-analysis. Journal of Abnormal Psychology, 119(1), 117.

Paquette, D. (2004). Theorizing the father-child relationship: Mechanisms and developmental outcomes. Human Development, 47, 193-219.

Patterson, G. R. (1982). Coercive family process. Eugene: Castalia.

Patterson, G. R. (2002). The early development of coercive family process. In J. B. Reid, G. R. Patterson, \& J. Snyder (Eds.), Antisocial behavior in children and adolescents: A developmental analysis and model for intervention (pp. 25-44). Washington, DC: American Psychological Association.

Patterson, G. R., DeGarmo, D. S., \& Knutson, N. (2000). Hyperactive and antisocial behaviors: Comorbid or two points in the same process? Development and Psychopathology, 12(1), 91-106.

Pettit, G. S., Bates, J. E., \& Doodge, K. A. (1997). Supportive parenting, ecological context, and children's adjustment: A seven-year longitudinal study. Child Development, 68, 908-923.

Racz, S. J., \& McMahon, R. J. (2011). The relationship between parental knowledge and monitoring and child and adolescent conduct problems: A 10-year update. Clinical Child and Family Psychology Review, 14(4), 377-398.

Rielly, N. E., Craig, W. M., \& Parker, K. C. (2006). Peer and parenting characteristics of boys and girls with subclinical attention problems. Journal of Attention Disorders, 9(4), 598-606.

Shelton, K. K., Frick, P. J., \& Wootton, J. (1996). Assessment of parenting practices in families of elementary school-age children. Journal of Clinical Child Psychology, 25(3), 317-329.

Smith, G. T. (2005). On construct validity: Issues of method and measurement. Psychological Assessment, 17(4), 396-408.

Sonuga-Barke, E. J. S., Oades, R. D., Psychogiou, L., Chen, W., Franke, B., Buitelaar, J., Banaschewski, T., Ebstein, R. P., Gil, M., Anney, R., Miranda, A., Roeyers, H., Rothenberger, A., Sergeant, J., Steinhausen, H. C., Thompson, M., Asherson, P., \& Faraone, S. V. 
(2009). Dopamine and serotonin transporter genotypes moderates sensitivity to maternal expressed emotion: The case of conduct and emotional problems in attention deficit/hyperactivity disorder. Journal of Child Psychology and Psychiatry, 50, 1052-1063.

Steiger, J. H. (1990). Structural model evaluation and modification: An interval estimation approach. Multivariate Behavioral Research, 25, 173-180.

Stormshak, E. A., Bierman, K. L., McMahon, R. J., \& Lengua, L. J. (2000). Parenting practices and child disruptive behavior problems in early elementary school. Journal of Clinical Child Psychology, 29(1), 17-29.

Strassberg, Z., Dodge, K. A., Pettit, G. S., \& Bates, J. E. (1994). Spanking in the home and children's subsequent aggression toward kindergarten peers. Development and Psychopathology, 6(3), 445-461.
Tucker, L. R., \& Lewis, C. (1973). A reliability coefficient for maximum likelihood factor analysis. Psychometrika, 38, 1-10.

Ullsperger, J. M., Nigg, J. T., \& Nikolas, M. a. (2016). Does child temperament play a role in association between parenting practices and child attention deficit/ hyperactivity disorder? Journal of Abnormal Child Psychology, 44, 167-178.

Zlomke, K. R., Lamport, D., Bauman, S., Garland, B., \& Talbot, B. (2014). Parenting adolescents: Examining the factor structure of the Alabama parenting questionnaire for adolescents. Journal of Child and Family Studies, 23(8), 1484-1490.

Publisher's note Springer Nature remains neutral with regard to jurisdictional claims in published maps and institutional affiliations. 